\title{
man \\ Influence of Pulsed Electric Fields on Photosynthesis in Light/Dark-Acclimated Lettuce
}

\author{
Douyan Wang ${ }^{1, *}{ }$, Yu Hayashi ${ }^{2}$, Takahiro Enoki ${ }^{2}$, Kenta Nakahara ${ }^{2}$, Tetsuya Arita ${ }^{1}$, Yuya Higashi ${ }^{1}$, \\ Yasuharu Kuno ${ }^{3}$, Tatsuya Terazawa ${ }^{3}$ and Takao Namihira ${ }^{1}$ (D) \\ 1 Institute of Industrial Nanomaterials, Kumamoto University, Kumamoto 860-8555, Japan; \\ tarita@cs.kumamoto-u.ac.jp (T.A.); yuyahiga@gmail.com (Y.H.); namihira@cs.kumamoto-u.ac.jp (T.N.) \\ 2 Graduate School of Science and Technology, Kumamoto University, Kumamoto 860-8555, Japan; \\ y.hayashi@st.cs.kumamoto-u.ac.jp (Y.H.); t.enoki@st.cs.kumamoto-u.ac.jp (T.E.); \\ k.nakahara@st.cs.kumamoto-u.ac.jp (K.N.) \\ 3 Energy Support Corporation, Aichi 484-8505, Japan; y-kuno@energys.co.jp (Y.K.); \\ t-terazawa@energys.co.jp (T.T.) \\ * Correspondence: douyan@cs.kumamoto-u.ac.jp
}

check for updates

Citation: Wang, D.; Hayashi, Y.; Enoki, T.; Nakahara, K.; Arita, T.; Higashi, Y.; Kuno, Y.; Terazawa, T.; Namihira, T. Influence of Pulsed Electric Fields on Photosynthesis in Light/Dark-Acclimated Lettuce. Agronomy 2022, 12, 173. https:/ / doi.org/10.3390/agronomy12010173

Academic Editor: Pedro

Javier Zapata

Received: 30 November 2021

Accepted: 7 January 2022

Published: 11 January 2022

Publisher's Note: MDPI stays neutral with regard to jurisdictional claims in published maps and institutional affiliations.

Copyright: (C) 2022 by the authors. Licensee MDPI, Basel, Switzerland. This article is an open access article distributed under the terms and conditions of the Creative Commons Attribution (CC BY) license (https:// creativecommons.org/licenses/by/ $4.0 /)$.

\begin{abstract}
Recent years have seen numerous studies into how applying pulsed high electric fields (PEF) to living organisms induces various stress reactions. Plants produce glucose through photosynthesis and use this as a source of energy for living, yet there are few studies on the photosynthetic response characteristics when PEF is applied to growing plants. In this study, the photosynthetic response when electric fields of 10 to $100 \mathrm{~V} / \mathrm{mm}$ were applied to light and dark-acclimated leaves of lettuce was measured by combined gas exchange and chlorophyll fluorescence, and the exposure time was kept constant at $500 \mathrm{~s}$. The responses to PEF with regard to the photosynthetic parameters of electron transfer rate (ETR), non-photochemical quenching (NPQ), photosynthetic rate (A), and transpiration rate $(\mathrm{E})$ were recorded during the experiment. Results showed that PEF can cause both the activation and deactivation of photosynthetic activity in lettuce, that there is an optimum value for activation, and that the application of excessive energy leads to inactivation. This study also found that stomata on both active and deactivated lettuce had been open to a greater extent than lettuce to which PEF had not been applied. All the results of statistical significance in this study were $p<0.05$ and $p<0.01$.
\end{abstract}

Keywords: leaf lettuce; chlorophyll fluorescence; electron transfer rate (ETR); non-photochemical quenching (NPQ); photosynthetic rate (A); transpiration rate (E); growth enhancement/inhibition

\section{Introduction}

Bioelectrics is the field of scientific study involving the application of pulsed power to living organisms. Bioelectrics has gained much attention in recent years and currently is the subject of many studies [1]. Pulsed power is the creation of high peak power by limiting the space and duration of electromagnetic energy and emitting it in an extremely short time. Pulsed power is characterized by a high power, high energy density, short rise time, and short pulse width. Applying pulsed power to living organisms creates instantaneous extreme conditions (including ultra-high voltages, ultra-high temperatures, and ultra-thermal nonequilibrium), thereby inducing extraordinary phenomena and reactions [2,3]. An example of this is a study that applied pulsed power to cancer cells to induce apoptosis $[4,5]$. Studies have also been done showing that, when applied to plants, PEF can promote seed germination and promote/inhibit plant growth [6-8]. In this way, applying pulsed power to living organisms can induce a variety of reactions, and there is great potential for innovation with this technology. However, much is still unknown regarding the relationship between pulsed power and the biomechanisms it affects, and research on growing plants is lacking. 
Plants are essential for the Controlled Ecological Life Support Systems (CELSS) that will make long-term manned space travel possible in the not-too-distant future. Lettuce has been considered a candidate for cultivation in CELSS as it is both easy to grow and offers good nutrition in its edible sections [9]. An enclosed cultivation space is necessary to rapidly cultivate a high volume of plants in a limited area in the environment of outer space, which differs considerably from conditions on Earth [10]. However, in order to establish environmental control technology for efficient plant production in CELSS, it is necessary to consider the effects of physical environmental factors and effects of environmental conditions unique to space on plant gas exchange and growth [10].

Lettuce is the best-suited candidate crop species to grow in a plant cultivator due to its low-light adaptability [11]. There has been a variety of research done on photosynthesis in lettuce, but research has been on light sources [12-15] and there is little information on how lettuce responds to PEFs [16].

Photosynthesis fixes atmospheric carbon dioxide and produces carbohydrates, part of which are catabolized into ATP and reductants by respiration in response to cellular energy demand [17]. Photosystem II (PSII) is a photosynthetic component that is highly sensitive to stress conditions; therefore, analysis of PSII function is very important for studying stress effects in plants $[18,19]$. Chlorophyll (Chl) a fluorescence, which originates from PSII reaction centers (RCs), is usually represented by a fast rise followed by a slow decline when exposed to light (Kautsky curve). Based on modulated fluorescence measurements, fluorescence quenching analysis has been developed, leading to the determination of parameters that can be used to evaluate both the structural differences between dark and light-acclimated states and the photosynthetic performance at the light-acclimated state [20].

The photosynthetic carbon reduction (Calvin) cycle is the primary pathway for carbon fixation and, in higher plants, occurs in the chloroplast stroma. The Calvin cycle utilizes the products of the light reactions of photosynthesis (ATP and NADPH) to fix atmospheric $\mathrm{CO}_{2}$ into carbon skeletons that are used directly for starch and sucrose biosynthesis [21]. As such, the simultaneous measurement and assessment of chlorophyll fluorescence and gas exchange in the Calvin cycle are useful for understanding external stress response mechanisms in plant photosynthesis.

Recent advancements in gas exchange measurement systems enable a wide range of users to quantify photosynthetic responses more reliably and easily [22,23]. Using a photosynthesis system (LI-6800, LICOR, Lincoln, NE, USA), this study aims to investigate how leaf photosynthesis is affected when lettuce is subjected to PEF.

\section{Materials and Methods}

\subsection{Plant Material and Growth Conditions}

Lettuce (Lactuca sativa L.) (Frillice, PR-(L), Snow Brand Seed Co., Ltd., Hokkaido, Japan) was chosen as the subject of this experimental study. The seeds were germinated and grown on sponge-like foamed urethane cuboids (M Hydroponic Research Co., Ltd., Aichi, Japan) steeped in liquid fertilizer (No. 1 and No. 2 mixture of OTSUKA HOUSE, OAT Agrio Co., Ltd., Tokyo, Japan) that was composed of No.1: $10 \% \mathrm{~N}, 8 \% \mathrm{P}_{2} \mathrm{O}_{5}, 27 \% \mathrm{~K}_{2} \mathrm{O}, 4 \% \mathrm{MgO}, 0.1 \%$ $\mathrm{MnO}, 0.1 \% \mathrm{~B}_{2} \mathrm{O}_{3}, 0.18 \% \mathrm{Fe}, 0.002 \% \mathrm{Cu}, 0.006 \% \mathrm{Zn}, 0.002 \% \mathrm{Mo}$, and No. $2: 11 \% \mathrm{~N}, 23 \% \mathrm{CaO}$ in a plastic tray (340 mm width, $140 \mathrm{~mm}$ depth, $60 \mathrm{~mm}$ height), then moved to a hydroponic grower (Green Farm, UH-A01E1, UING Corporation, Nara, Japan) on day 5, which was placed in a room at $20^{\circ} \mathrm{C}$ with a relative humidity of $50-80 \%$. Plants were established at $20{ }^{\circ} \mathrm{C}$ day/night temperatures and $50-80 \%$ relative humidity with a light-dark cycle of $16 \mathrm{~h}$ (light illumination of $150 \mu \mathrm{mol} / \mathrm{m}^{2} \mathrm{~s}$ ) and $8 \mathrm{~h}$ (darkness of $0 \mu \mathrm{mol} / \mathrm{m}^{2} \mathrm{~s}$ ) for 21 days (Figure 1). Liquid fertilizer (of the same composition as that used for seed germination) was added to the hydroponic grower to maintain a liquid level up to surface of the urethane cuboids to offset liquid evaporation during incubation. 


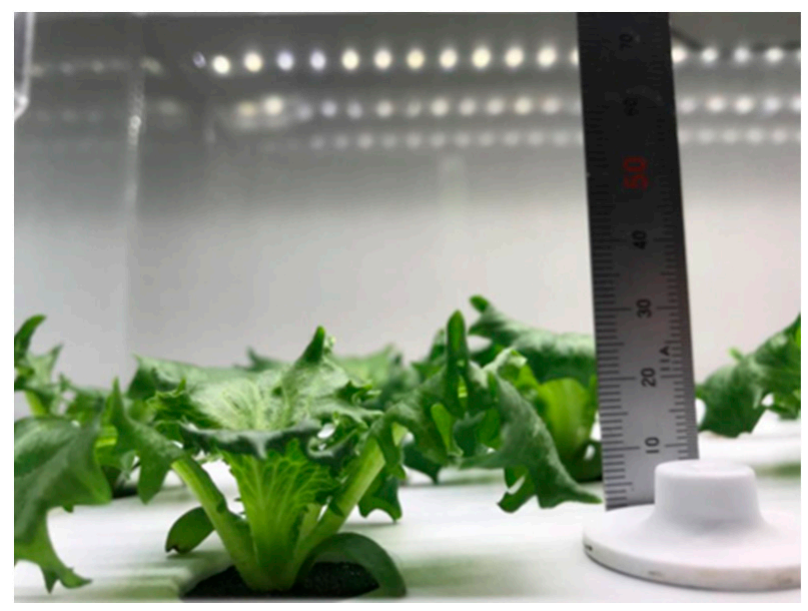

Figure 1. Lettuce on day 21 (the day of experiments). Lettuce seeds were germinated and grown on sponge-like foamed urethane cuboids steeped in liquid fertilizer in a plastic tray, then moved to a hydroponic cultivator on day 5 , which was placed in a room at $20{ }^{\circ} \mathrm{C}$ with a relative humidity of $50-80 \%$. Plants were established at $20^{\circ} \mathrm{C}$ day/night temperatures with $50-80 \%$ relative humidity with a light-dark cycle of $16 \mathrm{~h}$ (light) and $8 \mathrm{~h}$ (dark) for 21 days.

\subsection{Pulsed Electric Field Treatments}

Figure 2 is a diagram of the PEF treatment equipment used in this study. One lettuce plant with roots submerged in liquid fertilizer was placed between parallel plate electrodes, and a pulsed power generator connected to the electrodes was used to apply pulsed voltage between the electrodes. The plate electrodes consisted of $150 \mathrm{~mm} \times 150 \mathrm{~mm}, 4 \mathrm{~mm}$-thick stainless-steel plates, and $5 \mathrm{~mm}$-thick acrylic plates were attached to the metal to prevent discharge between the electrodes. The distance between the electrodes was $150 \mathrm{~mm}$. When treating the lettuce with PEF, it was necessary to avoid having a lettuce leaf come into contact with one of the electrodes and produce an abnormal electrical discharge. Our 21-day-old lettuce had a maximum leaf length of $130 \mathrm{~mm}$, so we placed our electrodes $150 \mathrm{~mm}$ apart to ensure adequate space.

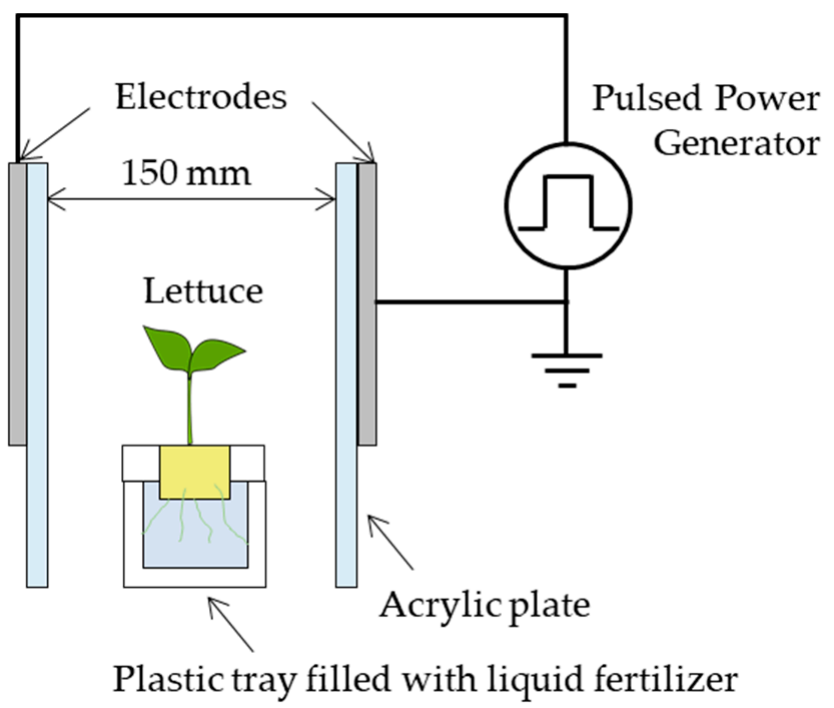

Figure 2. Schematic diagram of PEF treatment system. One lettuce plant with roots immersed in liquid fertilizer was placed between parallel plate electrodes, and a pulsed voltage was applied between the electrodes by a pulsed power generator connected to the electrodes. The plate electrodes are $150 \mathrm{~mm} \times 150 \mathrm{~mm} \times 4 \mathrm{~mm}$ stainless steel plates, and a $5 \mathrm{~mm}$-thick acrylic plate was installed to prevent discharge between the electrodes. The distance between the electrodes was $150 \mathrm{~mm}$. 
Figure 3 shows a schematic diagram of the purpose-built pulsed power generator used to generate pulsed electric fields in this study. The generator is based on an inductive energy storage (IES) system. Inductive energy storage (IES) is a method for obtaining steep pulses by passing a current through an inductor to store energy as a magnetic field, then abruptly cutting off the current. A unique aspect of this circuit is that an N-channel SiC power MOSFET (SCT3030KL, ROHM Co., Ltd., Kyoto, Japan) is used as the switch that acts as the current cutoff. This makes a faster current cutoff possible, which greatly affects the performance of the IES. Further, the use of a semiconductor switch extends the life of the device. The voltages and repetition frequencies of the output of the IES power supply were controlled using a function generator (20 MHz Function/Arbitrary Waveform Generator, 33220A, Agilent Technologies, Inc., Santa Clara, CA, USA). Electric field intensity was calculated by dividing the applied pulsed voltage by electrode distance. In this study, pulsed electric field intensities (PEF) applied between the electrodes were changed between values of $10,20,50,80$, and $100 \mathrm{~V} / \mathrm{mm}$, and the pulse repetition rate was set at either 1 pps (pulses per second) or 1000 pps for each PEF. In the experiment, the PEF application time per lettuce plant was kept constant at $500 \mathrm{~s}$. As such, lettuce samples subject to 1 pps received the energy of 500 pulses, and lettuce samples subject to 1000 pps received the energy of 500,000 pulses. The reason we set $100 \mathrm{~V} / \mathrm{mm}$ as the maximum PEF value is because, in our pre-experiment testing, values of $100 \mathrm{~V} / \mathrm{mm}$ and higher resulted in photosynthetic inhibition. We chose $10 \mathrm{~V} / \mathrm{mm}$ as the minimum value because it was the lowest voltage our power supply could reliably produce. The PEF application period was set at $500 \mathrm{~s}$ because, in our pre-experiment testing on times from 100 to $1000 \mathrm{~s}$, we achieved adequate photosynthetic reaction at $500 \mathrm{~s}$ (saturation tended to occur with application periods over $500 \mathrm{~s}$ ). The dielectric constant of the acrylic plates attached to the metal electrodes is about 3.0 (which is different from the air between the electrodes, that has a dielectric constant of 1.0). If the electrical field strength when applied through air was set at $100 \%$ without the acrylic plates, the strength was $104 \%$ with the acrylic plates. This difference was low enough that we did not factor in the effects of the acrylic plates when making calculations in this study.

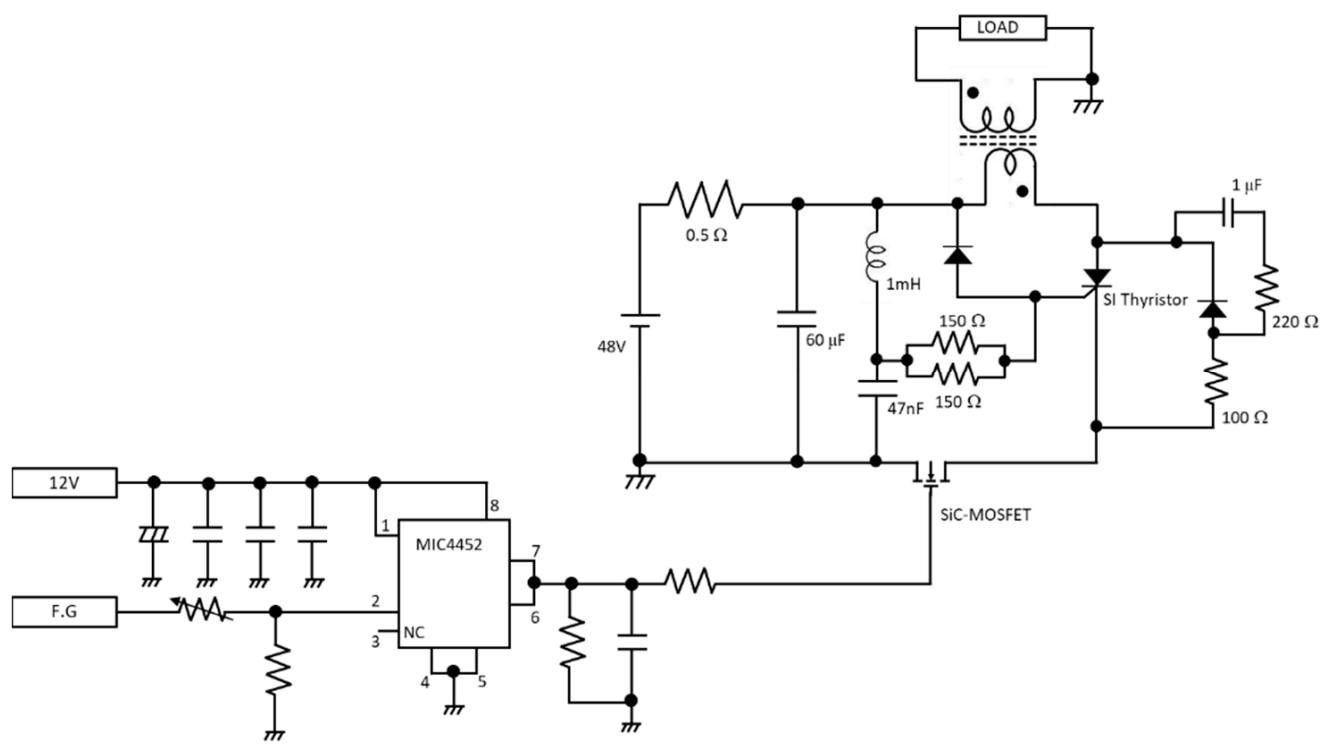

Figure 3. Schematic diagram of IES pulsed power generator used to generate PEF. The switch used for the inductive energy storage (IES) system was an $\mathrm{N}$-channel $\mathrm{SiC}$ power MOSFET.

\subsection{Combined Gas Exchange and Chlorophyll Fluorescence Measurements}

PEF-treated and untreated leaves were measured for gas exchange and chlorophyll fluorescence with a Portable Photosynthesis System (LI-6800, LI-COR Biosciences, Lincoln, NE, USA). Leaf samples were exposed to photosynthetic photon flux density (PPFD) at 
$150 \mu \mathrm{mol} / \mathrm{m}^{2} \mathrm{~s}$ for $60 \mathrm{~s}$ under $\left[\mathrm{CO}_{2}\right]$ of $400 \mu \mathrm{mol} / \mathrm{mol}$. The chamber temperature and humidity were $23^{\circ} \mathrm{C}$ and $50 \%$, respectively. Other chamber conditions were as follows: fan speed, 10,000 rpm; flow rate to the sample cell, $500 \mu \mathrm{mol}$ air $/ \mathrm{s}$; and overpressure, $0.1 \mathrm{kPa}$.

Chlorophyll fluorescence measurements were conducted at the same time as the gas exchange measurements with a multiphase flash fluorometer. A saturated pulsed light of $10,000 \mu \mathrm{mol} / \mathrm{m}^{2} \mathrm{~s}$ with $25 \%$ attenuation for $0.3 \mathrm{~s}$ was used at each of the three phases.

In this study, the electron transfer rate (ETR), non-photochemical quenching (NPQ), photosynthetic rate (A), and transpiration rate (E) were evaluated using the LI-6800 device.

\subsection{Dark/Light Acclimation}

To compare the effects of applying PEF under different light levels during lettuce cultivation, lettuce samples were given at least $1 \mathrm{~h}$ before the experiment to acclimate to either light $\left(150 \mu \mathrm{mol} / \mathrm{m}^{2} \mathrm{~s}\right)$ or dark $\left(0 \mu \mathrm{mol} / \mathrm{m}^{2} \mathrm{~s}\right)$ conditions [24]. PEF was applied under equivalent light/dark conditions, and photosynthetic parameters were measured immediately thereafter.

In the experiment, two sets of measurements were conducted each for light and dark acclimation over 5 different electrical field strengths $(10,20,50,80$, and $100 \mathrm{~V} / \mathrm{mm})$ and at 2 different pulse rates ( 1 pps and 1000 pps), for a total of 20 experimental conditions, with each parameter tested on at least $n=5$ lettuce samples. Further, to compare against the effect of PEFs, PEF was set at $0 \mathrm{~V} / \mathrm{mm}$ for the untreated group (control group, $n=15$ ). Aside from being treated with PEFs, the control samples were treated in the same way as the PEF-treated samples.

\subsection{Stomatal Aperture}

In the separate experiments, observations were made regarding the degree of stomata aperture [25]. To capture images of stomata, the abaxial epidermis was peeled off and floated with its inner surface facing down on a glass slide covered with basal buffer [50 mM KCl, $5 \mathrm{mM}$ Tris-MES, $\mathrm{pH}$ 6.5, and $10 \mathrm{mM} \mathrm{CaCl}_{2}$ ], and then covered by a cover glass (Matsunami Glass Ind., Ltd., Osaka, Japan). The slide was placed onto an inverted microscope (Eclipse TE2000-S, Nikon, Tokyo, Japan) equipped with a CFI Plan Fluor $20 \times$ ELWD, $40 \times$ ELWD, $60 \times$ ELWD objective lens and CFI $10 \times / 22$ eyepiece, together with a microscopy digital camera (DS-Ri2, Nikon, Tokyo, Japan). Stomatal aperture was measured on live images using the measurement tool of the microscope software (Nikon NIS-Elements Advanced Research, Ver. 4.60, Nikon Instruments Inc., Tokyo, Japan).

Observation of stomata opening/closing was conducted immediately after applying PEF to lettuce. Instead of measuring photosynthetic activity, the epidermis of the lettuce leaves was peeled off from the same site where the photosynthetic activity was to be measured; then, the specimen was mounted on a slide and observed under a microscope. Here, different lettuce was used for the PEF group and control group samples. The PEF application parameters were $10 \mathrm{~V} / \mathrm{mm}$ at $1 \mathrm{pps}$ and $100 \mathrm{~V} / \mathrm{mm}$ at $1000 \mathrm{pps}$ for both light and dark-acclimated samples, for a total of four sets. In the experiment, the number of pores evaluated was $n=100$ or greater for each parameter.

Stomatal aperture was measured by tracing the outline of the perimeter of the stomatal pore and the area inside the stomatal aperture was calculated using ImageJ (National Institutes of Health, Bethesda, MD, USA).

\subsection{Statistical Analysis}

Multiple lettuce samples were used under each experimental condition and average values were calculated. In addition, the Wilcoxon rank sum test (a nonparametric test) was performed on the measured values obtained under each condition in order to examine the statistically significant difference between the PEF-treated group and the untreated control group. For the test, $p$-values were calculated using R (Statistical Analysis Free Software " $\mathrm{R}$ ", $\mathrm{R}$ Development Core Team, The R Foundation) statistical analysis software. For data determined to be significant, $p<0.05$ is indicated by ${ }^{*}$ and $p<0.01$ is indicated by ${ }^{* *}$. 


\section{Results and Discussion}

\subsection{Output Waveforms of Applied Voltage and Current through the Electrode}

Figure 4 shows the output waveforms of applied voltage and current through the electrodes during PEF treatment. Figure 4 a shows the voltage and current waveforms at a pulse field strength of $10 \mathrm{~V} / \mathrm{mm}$, and Figure $4 \mathrm{~b}$ shows the voltage waveforms at all field strengths $(10,20,50,80,100 \mathrm{~V} / \mathrm{mm})$. In Figure 4a, the output voltage peak value is $1500 \mathrm{~V}$, and the pulse width (full width at half maximum, FWHM) is about $1 \mu \mathrm{s}$. Regarding the current waveform, the phase of the current is $\pi / 2$ earlier than the voltage because the electrodes are capacitive loads. Furthermore, since the medium between the electrodes is air and the impedance is close to infinity, it was found that for an applied voltage of $1500 \mathrm{~V}$, the peak value was about $10 \mathrm{~mA}$, indicating that almost no current was flowing, which matches the theoretical result. Figure $4 \mathrm{~b}$ also shows that peak voltages corresponding to the desired pulse electric field strength are being achieved between the electrodes. The reason that the voltage value is negative before the voltage rise time is due to the storage of energy in the inductor in the primary transformer of the IES circuit.

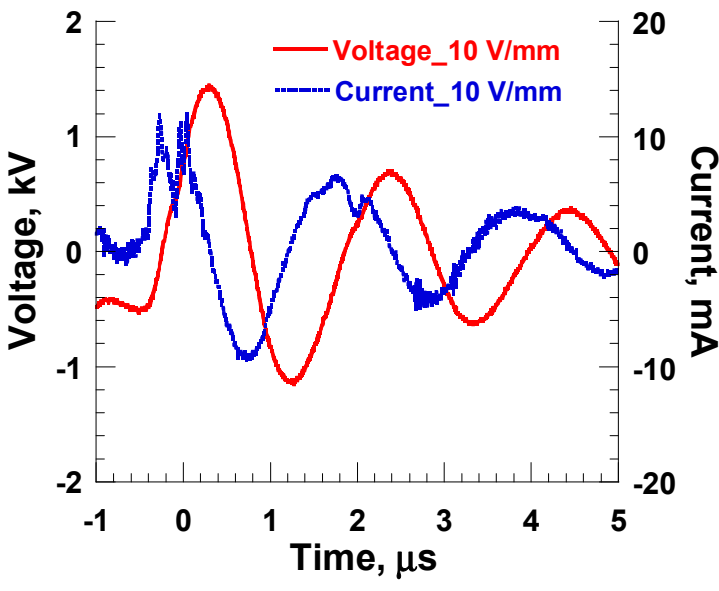

(a)

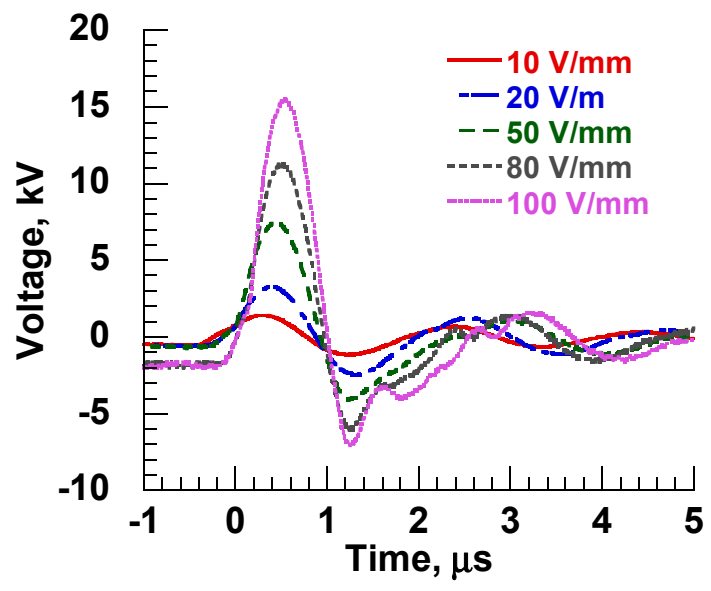

(b)

Figure 4. Output waveforms of applied voltage and current through the electrodes. (a) Typical applied voltage and current waveforms at $10 \mathrm{~V} / \mathrm{mm}$; (b) applied voltage waveforms for 10, 20, 50, 80, and $100 \mathrm{~V} / \mathrm{mm}$.

From the results in Figure 4, calculating the energy applied to each lettuce plant (total input energy per lettuce, $E_{\mathrm{t}}$ ) in each PEF application experiment using Equation (1) results in values of $0,0.001,0.0045,0.0295,0.077$, and $0.1495 \mathrm{~J}$ at $1 \mathrm{pps}$ and $1,4.5,29.5,77$, and $149.5 \mathrm{~J}$ at 1000 pps for field strengths of $10,20,50,80$, and $100 \mathrm{~V} / \mathrm{mm}$, respectively.

$$
E_{t}=\int V I d t \times \text { number of applied pulses }
$$

where $V$ and $I$ are the applied voltage and current through the electrodes.

\subsection{Effects of PEF Treatment on Photosynthesis in Light/Dark-Acclimated Lettuce}

Figure 5 shows a sample of the measurement results of combined gas exchange and chlorophyll fluorescence measurements. Figure 5 compares electron transport rate (ETR) results from the light-acclimated, PEF-treated samples against the control group and shows the saturation points for photosynthesis measurements when irradiated with excitation light. For PEF-treated lettuce, one leaf close to the high-voltage electrode was selected and sandwiched in the measurement chamber of the Portable Photosynthesis System for photosynthesis measurement. Each plot shows the value measured at a matching point. A matching point is first measured only when conditions inside the chamber $\left(\mathrm{CO}_{2}\right.$ concentration, $\mathrm{H}_{2} \mathrm{O}$ concentration, temperature) are stable, with irradiation with light effective in 
photosynthesis performed every $60 \mathrm{~s}$ on one leaf to obtain the photosynthesis parameters (for Figure 5, ETR). Therefore, the horizontal axis in Figure 5 represents measurements over time. From Figure 5, compared with the control group, the ETR of the $10 \mathrm{~V} / \mathrm{mm}$, 1 pps treated sample was significantly higher, and the ETR of the $100 \mathrm{~V} / \mathrm{mm}, 1000 \mathrm{pps}$ treated sample trended lower. In this study, the other photosynthetic parameters (nonphotochemical quenching (NPQ), photosynthetic rate (A), and transpiration rate (E)) were also plotted individually on the vertical axis (as in Figure 5), and the horizontal axis was set at the same number of exposures to saturated pulsed light. To save space, graphs related to other photosynthesis parameters are omitted here.

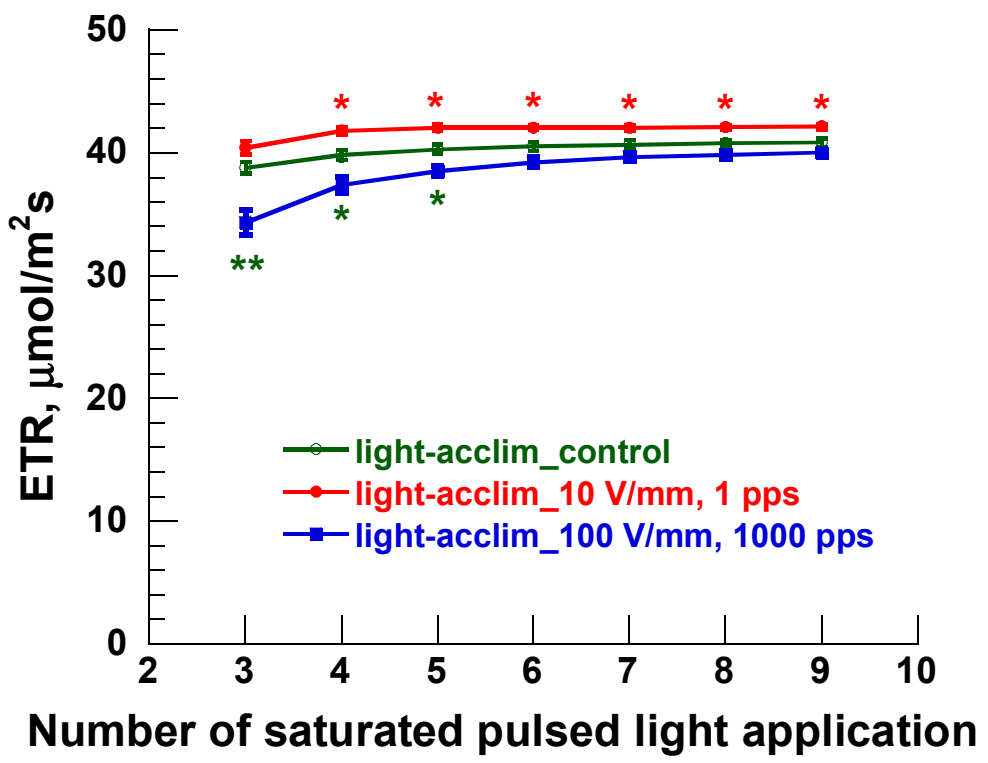

Figure 5. An example of photosynthetic parameters using the combined gas exchange and chlorophyll fluorescence measurements in this study. ETR results are given at each measurement time point (No.) for different PEF treatment conditions on light-acclimated samples. The asterisks * and ** indicate significant differences at $p<0.05$ and $p<0.01$, respectively.

The results of various PEF applications under different light acclimation conditions were analyzed with respect to each photosynthesis parameter, and the results are summarized in Figure 6 for easy viewing. The average values for photosynthesis measurements obtained under each experimental condition were calculated, and Figure 6 shows the increase or decrease of each value (as a percentage) with respect to the control group. Standard error values and average values are also included. The asterisks * and ${ }^{* *}$ indicate significant differences at $p<0.05$ and $p<0.01$, respectively. Increases are shown in red and decreases in blue. Figure 6a summarizes the experimental results that suggest photosynthetic activity, and Figure $6 \mathrm{~b}$ summarizes the experimental results suggesting deactivation of photosynthetic activity.

Here, relative ETR is an approximation of the rate of electrons pumped through the photosynthetic chain, and ETR has been found to be closely related to photosynthetic activity as measured by oxygen evolution or $\mathrm{CO}_{2}$ uptake [26]. Non-photochemical quenching $(\mathrm{NPQ})$ and the effective quantum yield of PSII ( $\left.\Phi_{\mathrm{PSII}}\right)$, which provide an indication of the amount of energy used in photochemistry, are correlated, where $\Phi_{\mathrm{PSII}}$ decreases with increasing irradiance as more electrons accumulate at the PSII acceptor side and there is a relative increase in non-photochemical quenching (heat energy dissipation) [27,28].

The rate of individual leaf photosynthesis (the rate of $\mathrm{CO}_{2}$ absorption across the area of a single leaf) is the most direct indicator of photosynthetic activity. Gas exchange on individual leaves mainly occurs via stomata, with $\mathrm{CO}_{2}$ absorption and water transpiration occurring simultaneously. Photosynthetic rate (A) and transpiration rate (E) can be measured directly with gas exchange measurements [29]. 
Photosynthesis Activation

\begin{tabular}{|c|c|c|c|c|}
\hline L & \multicolumn{4}{|c|}{$10 \mathrm{~V} / \mathrm{mm}, 1 \mathrm{pps}$} \\
\hline No. & ETR & NPQ & E & A \\
\hline 2 & $-18.8 \pm 1.82^{* *}$ & $70.8 \pm 0.06^{* *}$ & $6.6 \pm 0.00$ & $-23.7 \pm 0.30^{* *}$ \\
\hline 3 & $4.1 \pm 0.56$ & $1.6 \pm 0.05$ & $-6.1 \pm 0.00$ & $19.9 \pm 0.18^{*}$ \\
\hline 4 & $4.9 \pm 0.34^{*}$ & $-9.7 \pm 0.03$ & $2.7 \pm 0.00$ & $18.3 \pm 0.06^{* *}$ \\
\hline 5 & $4.4 \pm 0.31^{*}$ & $-3.7 \pm 0.03$ & $5.6 \pm 0.00$ & $10.6 \pm 0.13^{*}$ \\
\hline 6 & $3.8 \pm 0.24^{*}$ & $-1.6 \pm 0.02$ & $2.3 \pm 0.00$ & $6.3 \pm 0.06$ \\
\hline 7 & $3.3 \pm 0.23^{*}$ & $-0.3 \pm 0.01$ & $3.8 \pm 0.00$ & $6.4 \pm 0.10$ \\
\hline 8 & $3.2 \pm 0.23^{*}$ & $-0.4 \pm 0.01$ & $5.8 \pm 0.00$ & $7.7 \pm 0.07$ \\
\hline 9 & $3.2 \pm 0.24^{*}$ & $1.0 \pm 0.01$ & $5.7 \pm 0.00$ & $9.8 \pm 0.08$ \\
\hline D & \multicolumn{4}{|c|}{$10 \mathrm{~V} / \mathrm{mm}, 1000 \mathrm{pps}$} \\
\hline No. & ETR & NPQ & $\mathrm{E}$ & $\mathbf{A}$ \\
\hline 2 & $6.1 \pm 1.28$ & $-3.4 \pm 0.03$ & $-27.9 \pm 0.00$ & $16.3 \pm 0.28$ \\
\hline 3 & $2.6 \pm 0.60$ & $-10.1 \pm 0.03$ & $-17.3 \pm 0.00$ & $5.4 \pm 0.31$ \\
\hline 4 & $2.7 \pm 0.31$ & $-15.7 \pm 0.03$ & $-13.2 \pm 0.00$ & $8.4 \pm 0.30$ \\
\hline 5 & $2.8 \pm 0.21$ & $-16.7 \pm 0.02$ & $-12.3 \pm 0.00$ & $9.6 \pm 0.35$ \\
\hline 6 & $2.9 \pm 0.12 *$ & $-16.3 \pm 0.01^{*}$ & $-15.5 \pm 0.00$ & $6.2 \pm 0.32$ \\
\hline 7 & $2.7 \pm 0.13^{*}$ & $-14.3 \pm 0.01^{* *}$ & $-11.4 \pm 0.00$ & $7.8 \pm 0.24$ \\
\hline 8 & $2.5 \pm 0.15^{*}$ & $-11.0 \pm 0.00^{* *}$ & $-9.8 \pm 0.00$ & $6.7 \pm 0.28$ \\
\hline 9 & $2.5 \pm 0.14^{*}$ & $-8.5 \pm 0.00^{*}$ & $-9.8 \pm 0.00$ & $8.0 \pm 0.22$ \\
\hline
\end{tabular}

(a)
Photosynthesis Inactivation

\begin{tabular}{|c|c|c|c|c|}
\hline $\mathbf{L}$ & \multicolumn{4}{|c|}{$100 \mathrm{~V} / \mathrm{mm}, \mathbf{1 0 0 0}$ pps } \\
\hline No. & ETR & NPQ & E & A \\
\hline 2 & $-48.2 \pm 1.41^{* *}$ & $79.2 \pm 0.07^{* *}$ & $-29.6 \pm 0.00$ & $-53.6 \pm 0.13^{* *}$ \\
\hline 3 & $-11.5 \pm 0.99^{* *}$ & $111 \pm 0.05^{* *}$ & $-26.0 \pm 0.00$ & $-9.7 \pm 0.22$ \\
\hline 4 & $-6.0 \pm 0.62^{*}$ & $102 \pm 0.04^{* *}$ & $-23.3 \pm 0.00$ & $0.0 \pm 0.18$ \\
\hline 5 & $-4.4 \pm 0.45^{*}$ & $110 \pm 0.03^{* *}$ & $-21.1 \pm 0.00$ & $-7.8 \pm 0.11$ \\
\hline 6 & $-3.2 \pm 0.38$ & $101 \pm 0.02^{* *}$ & $-25.5 \pm 0.00$ & $-7.1 \pm 0.13$ \\
\hline 7 & $-2.5 \pm 0.34$ & $83.2 \pm 0.02^{* *}$ & $-20.9 \pm 0.00$ & $-4.6 \pm 0.16$ \\
\hline 8 & $-2.2 \pm 0.32$ & $69.7 \pm 0.02^{* *}$ & $-18.5 \pm 0.00$ & $-5.0 \pm 0.16$ \\
\hline 9 & $-2.0 \pm 0.28$ & $59.3 \pm 0.02^{* *}$ & $-18.8 \pm 0.00$ & $-1.3 \pm 0.17$ \\
\hline $\mathbf{D}$ & \multicolumn{5}{|c|}{$100 \mathrm{~V} / \mathrm{mm}, \mathbf{1 0 0 0}$ pps } \\
\hline No. & $\mathbf{E T R}$ & $\mathbf{N P Q}$ & $\mathbf{E}$ & $\mathbf{A}$ \\
\hline 2 & $-21.1 \pm 0.64^{* *}$ & $-3.0 \pm 0.05$ & $-44.2 \pm 0.00^{*}$ & $-18.5 \pm 0.35$ \\
\hline 3 & $-11.4 \pm 0.84^{* *}$ & $22.7 \pm 0.06$ & $-30.0 \pm 0.00^{*}$ & $-11.1 \pm 0.38$ \\
\hline 4 & $-7.0 \pm 0.63^{* *}$ & $29.6 \pm 0.06^{*}$ & $-25.9 \pm 0.00$ & $-9.8 \pm 0.36$ \\
\hline 5 & $-4.9 \pm 0.48^{*}$ & $27.0 \pm 0.05$ & $-27.2 \pm 0.00^{*}$ & $-6.9 \pm 0.37$ \\
\hline 6 & $-3.7 \pm 0.46^{*}$ & $18.5 \pm 0.03^{*}$ & $-30.6 \pm 0.00^{*}$ & $-2.3 \pm 0.35$ \\
\hline 7 & $-2.7 \pm 0.44^{*}$ & $7.7 \pm 0.02$ & $-25.8 \pm 0.00$ & $-0.1 \pm 0.28$ \\
\hline 8 & $-2.4 \pm 0.43$ & $1.9 \pm 0.01$ & $-25.5 \pm 0.00$ & $-1.1 \pm 0.23$ \\
\hline 9 & $-2.3 \pm 0.43$ & $-1.4 \pm 0.01$ & $-19.7 \pm 0.00$ & $-1.1 \pm 0.26$ \\
\hline
\end{tabular}

(b)

Figure 6. Characteristics of photosynthesis (a) activation and (b) inactivation after PEF treatments using the combined gas exchange and chlorophyll fluorescence measurements. Results used the average values of 15 samples for the control and 5 samples for each PEF-treated group. L: light-acclimated PEF samples; D: dark-acclimated PEF samples. Average values were calculated for photosynthesis measurement results obtained from each experiment, and the percentage of increase/decrease vs. the control group are listed. Increases are shown in red and decreases in blue. Standard error values and average values are also included. Asterisks ( ${ }^{*}$ and ${ }^{* *}$ ) indicate significant differences for $p<0.05$ and $p<0.01$, respectively. In (a), photosynthesis activation, ETR and A increased and NPQ decreased. In (b), photosynthesis inactivation, ETR and A decreased and NPQ increased.

From the above, this experiment defines photosynthetic activation as characterized by increases in ETR and photosynthetic rate A and a decrease in NPQ. Photosynthetic inactivation is characterized by decreases in ETR and photosynthetic rate A and an increase in NPQ.

Figure 7 shows heatmaps of photosynthetic parameters in the lettuce leaves treated with PEF. The heatmaps were drawn using the average of the values of 15 samples for the control and 5 samples for the PEF treatments. For each measurement time point (No.) and photosynthetic parameter (NPQ, ETR, A, E), the maximum absolute value of the difference between the control samples and PEF treated samples was set to 1. " $\mathrm{L}$ " indicates the samples that were light-acclimated and " $\mathrm{D}$ " indicates the samples that were dark-acclimated.

Figures 6 and 7 suggest that it is possible to elicit various patterns of response in lettuce by adjusting the PEF intensity. A closer look at Nos. 6 to 9 in the Figure 7 heatmap, where the differences in color are clearer, shows that the results can be divided into four patterns (patterns (1) through (4)). Combined with Figure 6, in pattern (1), ETR and A increased significantly and NPQ did not change much with PEF treatment $(10 \mathrm{~V} / \mathrm{mm}$, 1 pps) performed on light-acclimated specimens. This result suggests the possibility of photosynthetic activity. With the PEF treatment conditions $(20,50,80$, and $100 \mathrm{~V} / \mathrm{mm}$ at 1 pps) in pattern (2), no obvious changes were observed for both light-and dark-acclimated specimens, and no clear effect on photosynthetic activity/inactivity was seen. In pattern (3), for dark-acclimated samples treated with PEF (10, 20, $50 \mathrm{~V} / \mathrm{mm}, 1000$ pps), there was a significant increase in ETR and a significant decrease in NPQ, which suggests the possibility of photosynthetic activity. Similar results were observed by Sonoda et al., suggesting that the oxidation of plastoquinone might be promoted [16]. Considering Sonoda et al., nicotinamide adenine dinucleotide phosphate (NADPH), which is one of 
the essential molecules for the Calvin cycle, might be actively produced because the taken electrons are used for its generation, thus suggesting a possibility that the production of sucrose in the Calvin cycle may be increased and growth stimulation of leaf lettuce can be expected [16]. In pattern (4), for samples treated with high electric field strength and frequency $(80,100 \mathrm{~V} / \mathrm{mm}, 1000 \mathrm{pps})$, there was a significant increase in NPQ and decreasing trends for ETR and A in both light and dark-acclimated samples. This result suggests the possibility of photosynthetic inactivity.
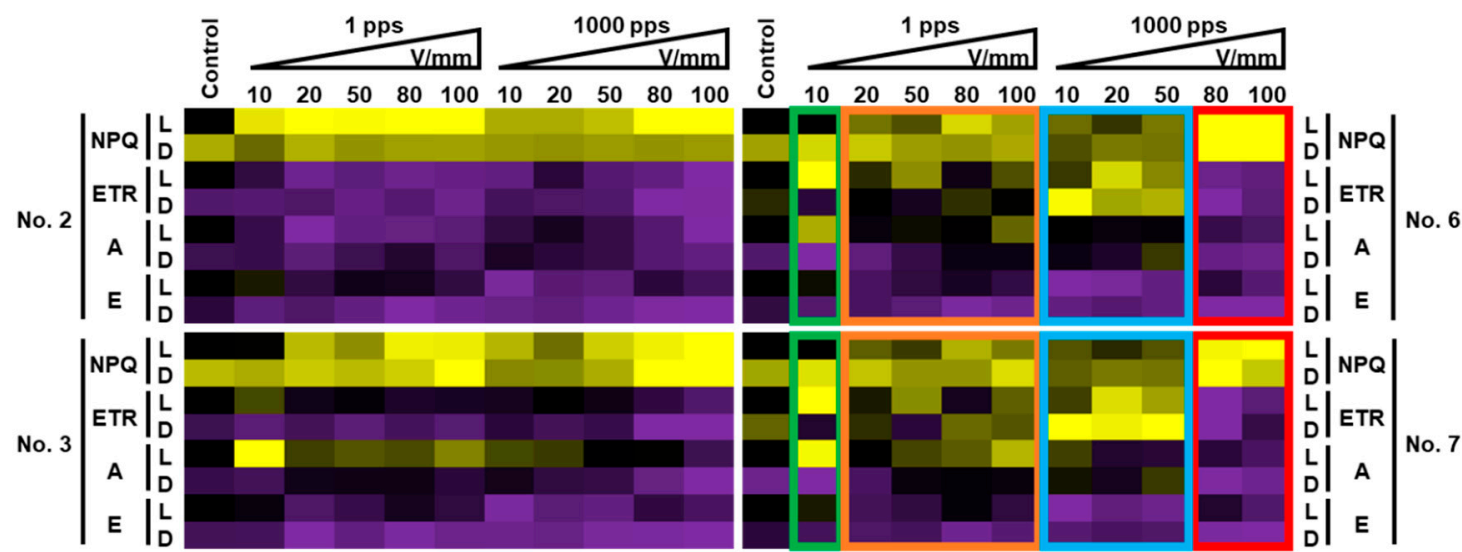

\begin{tabular}{l|l|l|l|l}
$\mathrm{D}$ & $\mathrm{NPQ}$
\end{tabular} L ETR No. 7
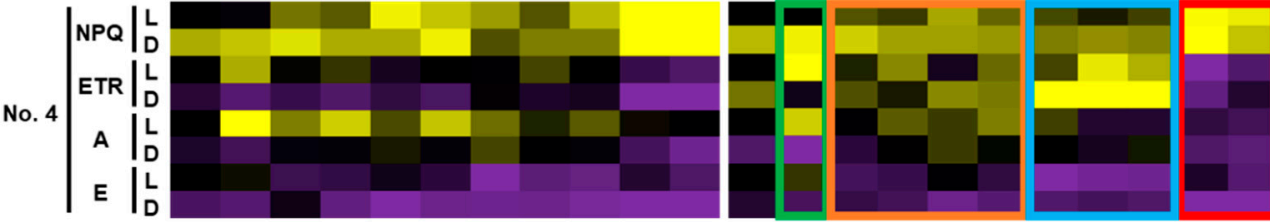

D A L 니№Q L ETR L $A$ L E
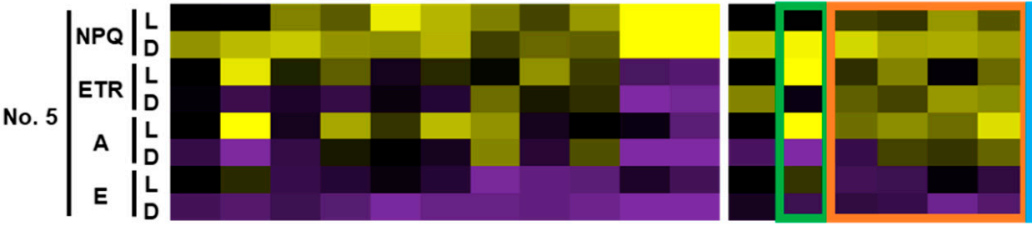
D E

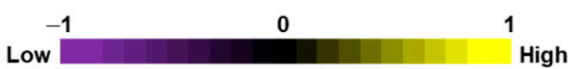

(1)

(2)

(4)

Figure 7. Heatmaps of photosynthetic parameters for lettuce leaves treated with PEF. The heatmaps were drawn using the average values of 15 samples for the control and 5 samples for each PEF-treated group. For each measurement time point (No.) and photosynthetic parameter (NPQ, ETR, A, E), the maximum absolute value of the difference between the control samples and PEF treated samples was set to 1. L: light-acclimated PEF samples; D: dark-acclimated PEF samples.

Figure 8 is a heatmap of photosynthetic rate $(\mathrm{A})$ made using the $E_{\mathrm{t}}$ values calculated with Equation (1) for individual lettuce plants under each of the PEF conditions. Figure 8 shows the degree of change in the measured photosynthetic rate A (values for PEF-treated samples minus the untreated sample value) divided by $E_{\mathrm{t}}$, which shows the level of photosynthetic reaction in the lettuce as it relates to the total amount of electrical energy applied. Yellow (activation) and purple (inactivation) indicate high reaction to total applied energy, and black indicates minimal reaction. Figure 8 shows that the $10 \mathrm{~V} / \mathrm{mm}, 1 \mathrm{pps}$ PEF application on light-acclimated samples yielded the most efficient photosynthetic activation, which agrees with the results obtained in Figure 7 pattern (1). Conversely, a trend for inactivation was observed when dark-acclimated samples were subjected to $10 \mathrm{~V} / \mathrm{mm}, 1$ pps PEF. For both light and dark-acclimated samples subjected to $100 \mathrm{~V} / \mathrm{mm}$, 1000 pps PEF (conditions equivalent to those of Figure 7 pattern (4)), the reaction to the total energy of the applied electrical fields was minimal. 


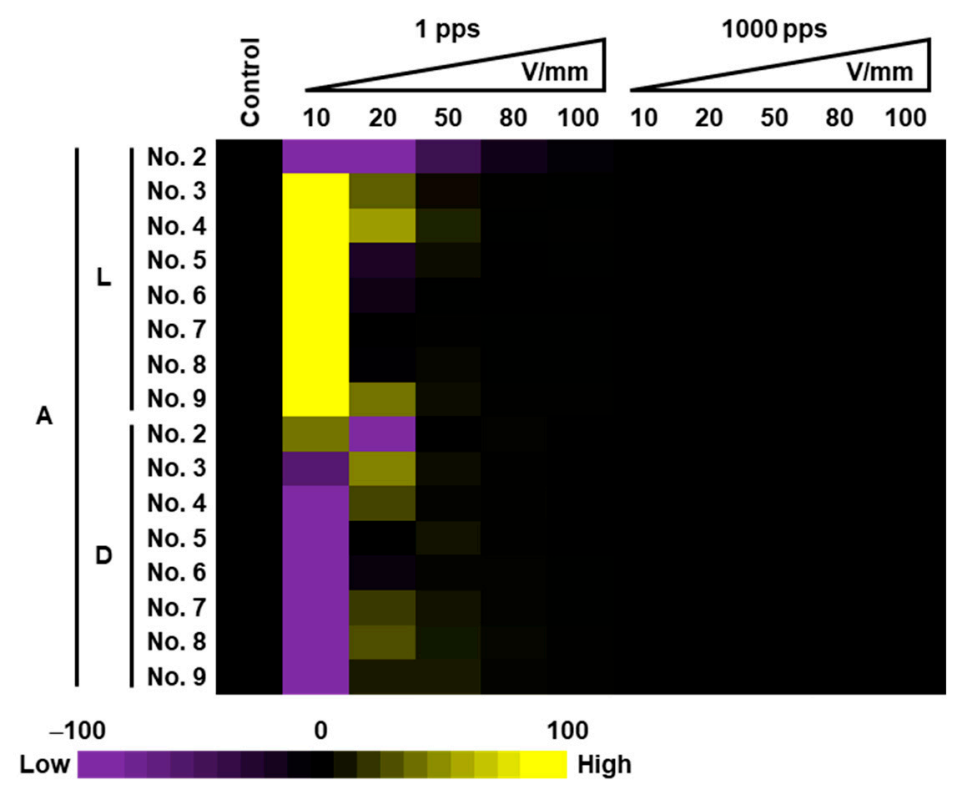

Figure 8. Heatmaps of photosynthetic rate A in the lettuce leaves treated with PEF. Heatmaps were drawn using the total input energy for one lettuce plant divided by the amount of change of $\mathrm{A}$ in Figure 7.

\subsection{Effect of PEF Treatment on Stomatal Aperture}

Stomatal aperture experiments were performed with the PEF application parameters given in Section 3.2, which suggested clear photosynthetic activity/inactivity $(10 \mathrm{~V} / \mathrm{mm}$, 1 pps and $100 \mathrm{~V} / \mathrm{mm}, 1000$ pps). The results of the experiment are shown in Figure 9. Figure 9a shows microscopic images of light-acclimated stomatal cells, Figure $9 \mathrm{~b}$ shows microscopic images of dark-acclimated stomatal cells, and Figure $9 \mathrm{c}$ is a bar graph of the stomatal aperture areas observed in all microscopic images. As seen in the microscopic images of Figure 9a,b, it is evident that stomatal aperture areas are larger than those of the control for each PEF application condition. Figure $9 \mathrm{c}$ also shows that these values are significant increases $(p<0.01)$ compared to the control.

Stomatal pores surrounded by a pair of guard cells in the plant epidermis control gas exchange between plants and the atmosphere in response to light, $\mathrm{CO}_{2}$, and abscisic acid-a plant hormone. Light-induced stomatal opening is mediated by at least three key components: the blue light receptor phototropin, plasma membrane $\mathrm{H}^{+}$-ATPase, and plasma membrane inward-rectifying $\mathrm{K}^{+}$channels. Stomatal aperture is a limiting factor in photosynthesis and plant growth [25].

R. Zvitov et al. observed stomatal opening as a result of the DC electrical field treatment of leaves, presumably due to the differential influence of the electrical treatment on the guard cell turgor pressure versus the turgor pressure of the surrounding epidermal cells [30]. Stephen Kwao et al. found that dehydration of basil leaves can be aided by the application of PEF. If the applied PEF conditions are such that stomata are irreversibly opened while the rest of the tissue remains viable, the drying process is faster, and the product keeps a better color, is richer in aroma compounds, and has better rehydration capacity than the untreated control [31].

\subsection{Photosynthetic Activation/Inactivation}

The results of Sections 3.2 and 3.3 can be divided into cases where photosynthesis was activated by PEF application and cases where it was inactivated, and we examine these separately. First, looking at the differences in results for samples acclimated to either light or dark conditions, there was only respiration with almost no photosynthetic activity for dark-acclimated samples, while there was active photosynthetic activity in light-acclimated samples. The primary electron acceptor $\left(\mathrm{Q}_{\mathrm{A}}\right)$ in PSII in chloroplasts is in a highly oxidized 
state (it loses electrons) when acclimated to the dark, but when acclimated to light, the $\mathrm{Q}_{\mathrm{A}}$ is highly reduced because it carries electrons (it receives electrons) [32,33].

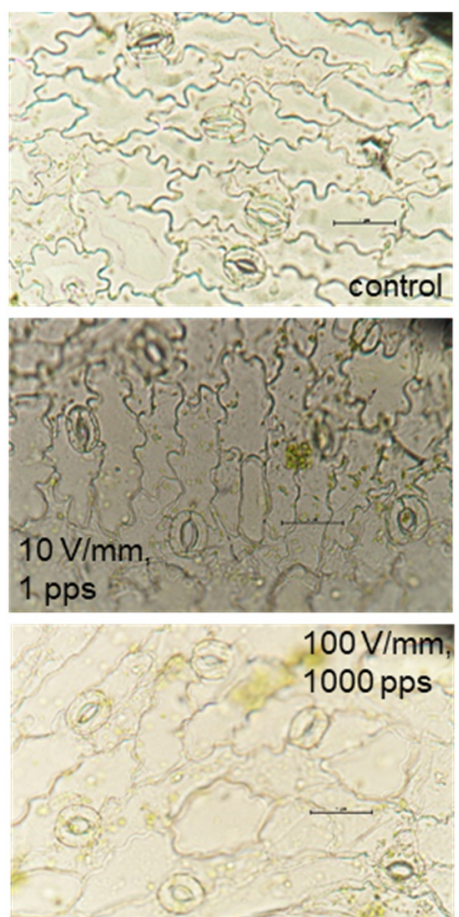

(a)
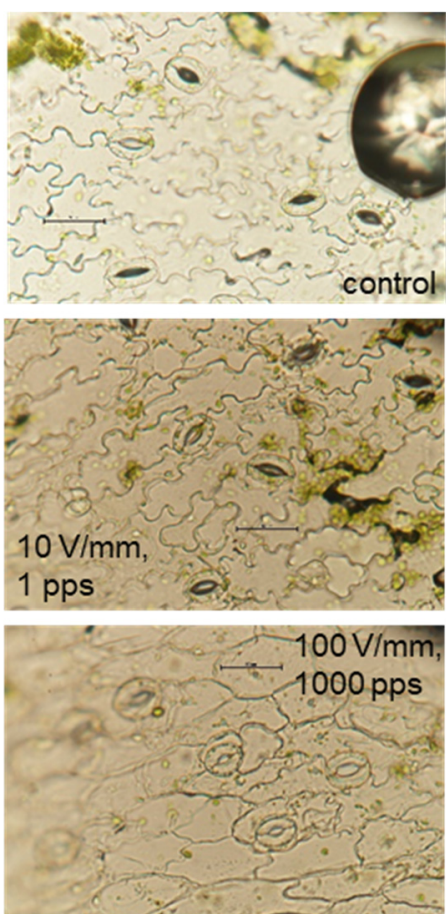

(b)

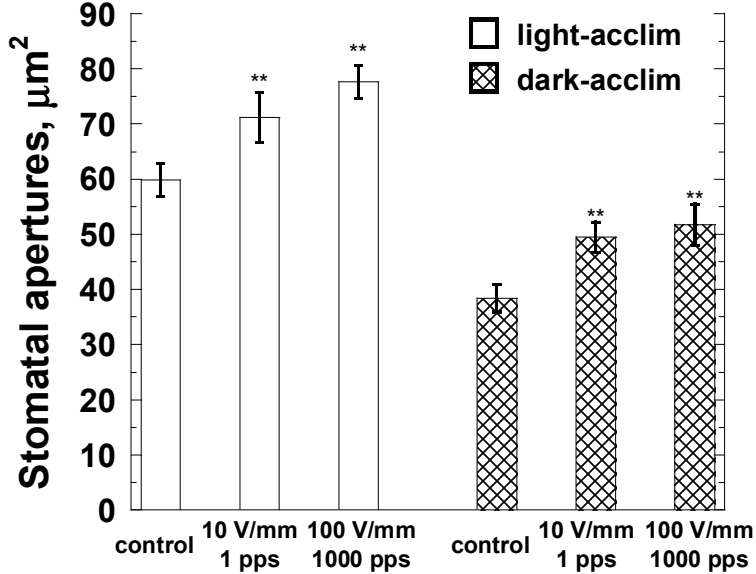

(c)

Figure 9. Microscopic images of typical guard cells subjected to varying PEF parameters in stomatal opening experiment. (a) Light-acclimated samples, (b) dark-acclimated samples. For both light and dark-acclimated samples, PEF application increased stomatal opening compared with the control group. Chart (c) shows the areas calculated using ImageJ after tracing the perimeters of the stomatal pores in the microscopic images. Significant increases in stomatal opening due to PEF application were observed in both light- and dark-acclimated samples. The asterisks $\left.{ }^{* *}\right)$ indicate significant differences at $p<0.01$.

\subsubsection{Photosynthetic Activation}

In Figure 7 pattern (1), where photosynthetic activity was observed, there was a significant increase in ETR and A. According to Sonoda et al., the cause of the increase in ETR is thought to be the activation of the electron transport chain, PSII, and plastoquinone, which is an electron transfer substance. Sonoda suggests that this may promote the reaction of redox substances present in the thylakoid membranes of chloroplasts, which is believed to be the same effect observed in this study [16]. For light-acclimated samples, where the ETR is steady because the $Q_{A}$ is highly reduced, the significant increase of ETR in the PEF-treated group compared to the control is believed to be due to the activation of the redox reaction of $Q_{A}$, leading to an increase in photosynthetic efficiency. In addition, the decrease in NPQ indicates that heat dissipation was suppressed, which in turn suggests that the irradiated light energy was efficiently used as energy for electron transfer. This then suggests that electron transfer occurred efficiently as a result of PEF application, which may have led to an increase in generation of the chemical energy molecules of ATP and NADPH. Zhao et al. also suggest that electric fields could affect photosynthesis, and the variance of photosynthetic rates mainly depends on the effect of external electric fields on the electron transport chain of photosynthesis, which is an important step in light reactions [34].

On the other hand, there are three possible factors for the increase in A. These are as follows: 1. an increase in $\mathrm{CO}_{2}$ uptake from outside of chloroplasts; 2. An increase in $\mathrm{CO}_{2}$ uptake due to increase in permeability of the chloroplast envelope (Rubisco activation) [35]; and 3. An increase in the generation of chemical energy due to an increased rate of 
electron transfer. For factor 1, because both ETR and transpiration rate E increased during activation for light-acclimated samples, it is possible that $\mathrm{CO}_{2}$ uptake increased due to gas exchange with the areas outside of chloroplasts. In addition, the results of the stomatal opening/closing experiment confirm that $\mathrm{CO}_{2}$ uptake increased because the degree of stomatal opening increased with the application of PEFs. According to Wu et al. [36], the capacity for plants to generate negative air ions (NAI) was significantly enhanced with PEF stimulation, and there was a close correlation between the capacity of the plant to generate NAI and the characteristics of leaf stomas. Under optimal PEF parameters, with wider stomata openings, the plant generated more NAI. The capacity of plants to release NAI was influenced by such elements as PEF, light intensity, and plant characteristics. PEF has a greater effect than other factors on the plant. Tikhonov et al. [37] and Wu et al. [38] also reported that plants generate more NAI with both PEF and light stimulation. For factor 2, Rubisco activation is known to be due to increased ETR [31]. Although not directly measured in this study, Rubisco activation by elevated ETR is possible [39]. For factor 3, fluctuations in chemical energy production are closely related to ETR. Electrons, together with hydrogen ions and oxygen molecules, are generated by the splitting of water in the lumen of chloroplast thylakoids. Then, electrons are transported via various proteins and combined on the thylakoid membrane with NADP+ and hydrogen ions to create NADPH. In addition, hydrogen ions generated by water splitting are used to bind ADP and phosphate by ATP synthase to produce ATP. Therefore, it is believed increased ETR contributes to the generation of chemical energy, and because the Calvin cycle operates using this chemical energy, this in turn affects the increase in the photosynthetic rate A. It is clear from Figure 8 that the PEF parameters for inducing such photosynthetic activity are $10 \mathrm{~V} / \mathrm{mm}$ and 1 pps, which creates an ideal reaction for plants to produce photosynthetic products. This means that it is possible to increase photosynthetic activity with a small amount of applied energy, and this could be considered a promising tool for efficiently improving the productivity of plants.

\subsubsection{Photosynthetic Inactivation}

In pattern (4) of Figure 7, in which photosynthetic inactivity was observed clearly, NPQ increased significantly due to PEF application. NPQ is a parameter that indicates fluctuations in heat dissipation, and it has been found that light absorption decreases as heat dissipation increases $[40,41]$. Chemical energy is required for carbon fixation in the Calvin cycle. Conversely, if the supply of $\mathrm{CO}_{2}$ to the Calvin cycle is delayed, carbon fixation does not occur and Calvin cycle activity ceases. At such times, if light energy reaching the PSII is not controlled, unused electrons and chemical energy are generated, which are then used outside of the Calvin cycle. One result is that oxygen molecules are converted to reactive oxygen, which can damage membrane lipids and enzymes inside chloroplasts. The system to prevent this is heat dissipation. Changes in NPQ after the absorption of light energy are believed to be due to heat dissipation, such as via the xanthophyll cycle, which affects the efficiency of energy transfer to PSII.

B.F. Marin et al. have reported that pulsed electric fields affect the total carotenoid amount and $\mathrm{pH}$ [41]. The xanthophyll cycle consists of carotenoids (pigments). Based on environmental conditions, this determines whether to convert between three carotenoids (violaxanthin, antheraxanthin, and zeaxanthin) to dissipate supplied light energy as heat. The de-epoxidation of xanthophylls is induced by a decrease of $\mathrm{pH}$ in the thylakoid lumen. De-epoxidation enzymes become activated in bright light, which convert violaxanthin to the reduced states such as antheraxanthin and zeaxanthin. The xanthophylls become reduced states as a result of the $\mathrm{pH}$ decrease in the thylakoid lumen, which dissipates energy as heat. Conversely, epoxidation enzymes become activated in low light, converting zeaxanthin to the oxidized states such as antheraxanthin and violaxanthin. The xanthophylls become oxidized by $\mathrm{pH}$ increase in the thylakoid lumen, which diverts energy to PSII. The increased NPQ in the PEF samples suggests that the $\mathrm{pH}$ of the thylakoid lumen might be affected, which promotes the activity of de-epoxidation enzymes and distributes 
more energy to heat dissipation. According to Liu et al. [42], there was a clear inhibition of photosynthetic activity in microalgae after applying external voltage, which affected microalgae growth. NPQ would increase as a protection mechanism against the excessive generation of electrons. When photochemistry is inhibited, energy dissipation through NPQ is enhanced, and therefore its values increase.

Gateau et al. employed a PEF of $100 \mathrm{~V} / \mathrm{mm}$ to extract proteins from living cells of green microalga [43]. They found that the application of PEF resulted in a $22.5 \%$ reduction in the respiratory rate value compared to the control. The photosynthetic oxygen evolution and $F_{\mathrm{v}} / F_{\mathrm{m}}$ ratio after PEF treatment first decreased and then reached a stationary level with field strengths greater than or equal to $100 \mathrm{~V} / \mathrm{mm}$. The PEF treatment also affected the functioning of cell organelles, especially that of the chloroplasts. They surmised that the decrease in the photosynthetic activity values may be partly due to disturbances in the photosynthetic electron transport chain, either through charge accumulation on the membranes or due to a reduction in the availability of electron transport proteins, such as the ferredoxin-NADP ${ }^{+}$reductase which catalyzes the reduction of $\mathrm{NADP}^{+}$to NADPH at the stromal side of PSI. The putative reduction in the production capacity of ATP and NADPH in the photobiochemical phase of photosynthesis can be expected to impact the production of triose phosphate in the Calvin cycle. Therefore, the cell's production capacity of simple sugars, which are either used as an immediate energy source or for the synthesis of larger cellular building blocks, is likely also reduced.

It is also possible that increased heat dissipation leads to a decrease in energy distributed to electron transport, suggesting a decrease in chemical energy production. This is believed to be a potential reason for the decrease in carbon fixation (confirmed by the decrease in ETR and A). Regarding the results of the experiment where photosynthetic activity was observed and stomatal opening increased even when PEF had been applied, $\mathrm{CO}_{2}$ uptake into the plant would not occur properly even if the stomata were open, meaning it did not achieve an increased photosynthetic rate.

\section{Conclusions}

This study provides important evidence on the response of plant photosynthetic activity to pulsed electric fields (PEF). From the experimental results, PEF was found to affect the photosynthetic mechanisms in lettuce. There are optimal values for photosynthetic activation, and excess energy can lead to inactivation. The results of this study revealed the following:

- When PEF (10 V/mm, 1 pps) was applied to light-acclimated samples, both ETR and A increased and NPQ did not change. This indicates the activation of photosynthetic activity.

- When PEF (10, 20,50 V/mm, 1000 pps) was applied to dark-acclimated samples, ETR increased and NPQ decreased.

- When PEF (80,100 V/mm, 1000 pps) was applied to both light and dark-acclimated samples, NPQ increased and ETR and A decreased. This indicates the inactivation of photosynthesis.

A possible cause for photosynthetic activation is that the application of PEF caused an increase in ETR, which led to an increase in chemical energy (ATP and NADPH). In addition, the observation that there was an increase in stomatal aperture demonstrates that $\mathrm{CO}_{2}$ increased and carbon fixation progressed.

A possible cause for the inactivation of photosynthetic activity is that heat dissipation increased due to de-epoxidation. Conversely, although it was observed that stomata opening increased with the application of PEF, it seems that $\mathrm{CO}_{2}$ uptake into the plant did not occur properly and carbon fixation was not achieved.

This study suggests the potential for using PEF to control the activation/inactivation of photosynthesis in lettuce. Our results lay a foundation for the study of influence of PEF on photosynthesis and help find ways to control photosynthetic activity in plants. 
This study measured the photosynthetic reaction immediately following the application of PEF and evaluated the effects on photosynthetic activity. As stated in the Introduction, if our research on controlling photosynthetic activity in lettuce using electrical energy can be applied to controlling the growth of plants, our research may be put to use in CELSS vegetable cultivation. As the first step toward achieving this, in addition to measuring results immediately after PEF treatment as in this study, we hope to perform research into long-term results when PEF is applied over long periods during lettuce cultivation.

\begin{abstract}
Author Contributions: Conceptualization, D.W., Y.H. and T.N.; methodology, D.W. and Y.H.; validation, D.W.; formal analysis, D.W., Y.H., Y.H. and T.N.; investigation, Y.H., T.E., K.N. and T.A.; resources, Y.H., T.E. and K.N.; data curation, Y.H., T.E., T.A. and Y.H.; writing-original draft preparation, D.W., Y.H.; writing—review and editing, D.W., Y.H. and T.N; visualization, D.W., Y.H., T.E., T.A. and Y.H.; supervision, D.W. and T.N.; project administration, D.W., T.N., Y.K. and T.T.; funding acquisition, D.W. and T.N. All authors have read and agreed to the published version of the manuscript.
\end{abstract}

Funding: This work was partially supported by JSPS KAKENHI Grant Number 19H05611 and a joint research fund from Energy Support Corporation, Japan.

Institutional Review Board Statement: Not applicable.

Informed Consent Statement: Not applicable.

Data Availability Statement: Not applicable.

Conflicts of Interest: The authors declare no conflict of interest.

\title{
References
}

1. Akiyama, H.; Heller, R. (Eds.) Bioelectrics; Springer: Tokyo, Japan, 2017; ISBN 978-4-431-56095-1.

2. Bluhm, H. Pulsed Power Systems Principles and Applications; Power Systems; Springer: Berlin/Heidelberg, Germany, 2006; ISBN 978-3-540-34662-3.

3. Akiyama, H.; Katsuki, S.; Redondo, L.; Akiyama, M.; Pemen, A.J.M.; Huiskamp, T.; Beckers, F.J.C.M.; van Heesch, E.J.M.; Winands, G.J.J.; Voeten, S.J.; et al. Pulsed Power Technology. In Bioelectrics; Akiyama, H., Heller, R., Eds.; Springer: Tokyo, Japan, 2017; pp. 41-107, ISBN 978-4-431-56095-1.

4. Joshi, R.P.; Schoenbach, K.H. Bioelectric Effects of Intense Ultrashort Pulses. Crit. Rev. Biomed. Eng. 2010, 38, 255-304. [CrossRef]

5. Schoenbach, K.H.; Hargrave, S.J.; Joshi, R.P.; Kolb, J.F.; Nuccitelli, R.; Osgood, C.; Pakhomov, A.; Stacey, M.; Swanson, R.J.; White, J.A.; et al. Bioelectric Effects of Intense Nanosecond Pulses. IEEE Trans. Dielectr. Electr. Insul. 2007, 14, 1088-1109. [CrossRef]

6. Songnuan, W.; Kirawanich, P. Early growth effects on Arabidopsis thaliana by seed exposure of nanosecond pulsed electric field. J. Electrost. 2012, 70, 445-450. [CrossRef]

7. $\quad$ Eing, C.J.; Bonnet, S.; Pacher, M.; Puchta, H.; Frey, W. Effects of nanosecond pulsed electric field exposure on arabidopsis thaliana. IEEE Trans. Dielectr. Electr. Insul. 2009, 16, 1322-1328. [CrossRef]

8. Sonoda, T.; Takamura, N.; Wang, D.; Namihira, T.; Akiyama, H. Growth Control of Leaf Lettuce Using Pulsed Electric Field. IEEE Trans. Plasma Sci. 2014, 42, 3202-3208. [CrossRef]

9. Zeidler, C.; Vrakking, V.; Bamsey, M.; Poulet, L.; Zabel, P.; Schubert, D.; Paille, C.; Mazzoleni, E.; Domurath, N. Greenhouse Module for Space System: A Lunar Greenhouse Design. Open Agric. 2017, 2, 116-132. [CrossRef]

10. Kitaya, Y. Plants to support long-term manned space activities. BSJ-Rev. 2020, 11, 90-105.

11. Azad, M.O.K.; Kjaer, K.H.; Adnan, M.; Naznin, M.T.; Lim, J.D.; Sung, I.J.; Park, C.H.; Lim, Y.S. The Evaluation of Growth Performance, Photosynthetic Capacity, and Primary and Secondary Metabolite Content of Leaf Lettuce Grown under Limited Irradiation of Blue and Red LED Light in an Urban Plant Factory. Agriculture 2020, 10, 28. [CrossRef]

12. Viršilè, A.; Brazaitytè, A.; Vaštakaitè-Kairienè, V.; Miliauskienė, J.; Jankauskienè, J.; Novičkovas, A.; Laužikè, K.; Samuolienè, G. The distinct impact of multi-color LED light on nitrate, amino acid, soluble sugar and organic acid contents in red and green leaf lettuce cultivated in controlled environment. Food Chem. 2020, 310, 125799. [CrossRef]

13. Pennisi, G.; Orsini, F.; Blasioli, S.; Cellini, A.; Crepaldi, A.; Braschi, I.; Spinelli, F.; Nicola, S.; Fernandez, J.A.; Stanghellini, C.; et al. Resource use efficiency of indoor lettuce (Lactuca sativa L.) cultivation as affected by red:blue ratio provided by LED lighting. Sci. Rep. 2019, 9, 14127. [CrossRef]

14. Han, T.; Vaganov, V.; Cao, S.; Li, Q.; Ling, L.; Cheng, X.; Peng, L.; Zhang, C.; Yakovlev, A.N.; Zhong, Y.; et al. Improving “color rendering" of LED lighting for the growth of lettuce. Sci. Rep. 2017, 7, 45944. [CrossRef]

15. Darko, É.; Heydarizadeh, P.; Schoefs, B.; Sabzalian, M.R. Photosynthesis under artificial light: The shift in primary and secondary metabolism. Philos. Trans. R. Soc. B Biol. Sci. 2014, 369, 20130243. [CrossRef] [PubMed]

16. Sonoda, T.; Higashi, Y.; Yamada, Y.; Wang, D.; Namihira, T.; Akiyama, H. Influence of Pulsed Electric Field to Leaf Lettuce Evaluated on Chlorophyll Fluorescence Measurement Using Pulsed-Amplitude-Modulated Fluorometer. Int. J. Plasma Environ. Sci. Technol. 2017, 11, 81-86. 
17. Noguchi, K.; Yoshida, K. Interaction between photosynthesis and respiration in illuminated leaves. Mitochondrion 2008, 8, 87-99. [CrossRef] [PubMed]

18. Stirbet, A. On the relation between the Kautsky effect (chlorophyll a fluorescence induction) and Photosystem II: Basics and applications of the OJIP fluorescence transient. J. Photochem. Photobiol. B Biol. 2011, 104, 236-257. [CrossRef] [PubMed]

19. Strasser, R.J.; Tsimilli-Michael, M.; Srivastava, A. Analysis of the Chlorophyll a Fluorescence Transient. In Chlorophyll a Fluorescence: A Signature of Photosynthesis; Papageorgiou, G.C., Govindjee, Eds.; Advances in Photosynthesis and Respiration; Springer: Dordrecht, The Netherlands, 2004; pp. 321-362. ISBN 978-1-4020-3218-9.

20. Schreiber, U. Pulse-Amplitude-Modulation (PAM) Fluorometry and Saturation Pulse Method: An Overview. In Chlorophyll a Fluorescence: A Signature of Photosynthesis; Papageorgiou, G.C., Govindjee, Eds.; Advances in Photosynthesis and Respiration; Springer: Dordrecht, The Netherlands, 2004; pp. 279-319. ISBN 978-1-4020-3218-9.

21. Raines, C.A. The Calvin cycle revisited. Photosynth. Res. 2003, 75, 1-10. [CrossRef]

22. Ikawa, H.; Sakai, H.; Chen, C.P.; Soong, T.H.; Yonemura, S.; Taniguchi, Y.; Yoshimoto, M.; Tokida, T.; Zhang, G.; Kuwagata, T.; et al. High mesophyll conductance in the high-yielding rice cultivar Takanari quantified with the combined gas exchange and chlorophyll fluorescence measurements under free-air $\mathrm{CO}_{2}$ enrichment. Plant Prod. Sci. 2019, 22, 395-406. [CrossRef]

23. Luo, H.-H.; Merope, T.-M.; Zhang, Y.-L.; Zhang, W.-F. Combining gas exchange and chlorophyll a fluorescence measurements to analyze the photosynthetic activity of drip-irrigated cotton under different soil water deficits. J. Integr. Agric. 2016, 15, 1256-1266. [CrossRef]

24. Bielczynski, L.W.; Schansker, G.; Croce, R. Effect of Light Acclimation on the Organization of Photosystem II Super- and Sub-Complexes in Arabidopsis thaliana. Front. Plant Sci. 2016, 7, 105. [CrossRef]

25. Wang, Y.; Noguchi, K.; Ono, N.; Inoue, S.-I.; Terashima, I.; Kinoshita, T. Overexpression of plasma membrane H+-ATPase in guard cells promotes light-induced stomatal opening and enhances plant growth. Proc. Natl. Acad. Sci. USA 2014, 111, 533-538. [CrossRef]

26. Beer, S.; Björk, M.; Gademann, R.; Ralph, P. Chapter 9-Measurements of Photosynthetic Rates in Seagrasses. In Global Seagrass Research Methods; Short, F.T., Coles, R.G., Eds.; Elsevier Science: Amsterdam, The Netherlands, 2001; pp. 183-198. ISBN 978-0-444-50891-1.

27. Ralph, P.J.; Gademann, R. Rapid light curves: A powerful tool to assess photosynthetic activity. Aquat. Bot. 2005, 82, 222-237. [CrossRef]

28. Moustaka, J.; Moustakas, M. Photoprotective mechanism of the non-target organism Arabidopsis thaliana to paraquat exposure. Pestic. Biochem. Physiol. 2014, 111, 1-6. [CrossRef]

29. Tanaka, Y. Measurements and its Applications of Leaf Gas Exchange. Jpn. J. Crop Sci. 2016, 85, 339-346. [CrossRef]

30. Zvitov, R.; Schwartz, A.; Zamski, E.; Nussinovitch, A. Direct Current Electrical Field Effects on Intact Plant Organs. Biotechnol. Prog. 2003, 19, 965-971. [CrossRef]

31. Kwao, S.; Al-Hamimi, S.; Damas, M.E.V.; Rasmusson, A.G.; Galindo, F.G. Effect of guard cells electroporation on drying kinetics and aroma compounds of Genovese basil (Ocimum basilicum L.) leaves. Innov. Food Sci. Emerg. Technol. 2016, 38, 15-23. [CrossRef]

32. Butler, W.L.; Kitajima, M. Fluorescence quenching in Photosystem II of chloroplasts. Biochim. Biophys. Acta (BBA) Bioenerg. 1975, 376, 116-125. [CrossRef]

33. Oxborough, K.; Baker, N.R. Resolving chlorophyll a fluorescence images of photosynthetic efficiency into photochemical and non-photochemical components-Calculation of qP and Fv-/Fm-; without measuring Fo-. Photosynth. Res. 1997, 54, 135-142. [CrossRef]

34. Zhao, L.; Liu, W.; Lian, J.; Shen, M.; Huo, X. Effects of electric fields on Cd accumulation and photosynthesis in Zea mays seedlings. J. Environ. Manag. 2020, 276, 111328. [CrossRef]

35. Suganami, M.; Suzuki, Y.; Kondo, E.; Nishida, S.; Konno, S.; Makino, A. Effects of Overproduction of Rubisco Activase on Rubisco Content in Transgenic Rice Grown at Different N Levels. Int. J. Mol. Sci. 2020, 21, 1626. [CrossRef]

36. Wu, R. Research on Generation of Negative Air Ions by Plants and Stomatal Characteristics under Pulsed Electrical Field Stimulation. IJAB 2017, 19, 1235-1245. [CrossRef]

37. Tikhonov, V.P.; Tsvetkov, V.D.; Litvinova, E.G.; Sirota, T.V.; Kondrashova, M.N. Generation of Negative Air Ions by Plants upon Pulsed Electrical Stimulation Applied to Soil. Russ. J. Plant Physiol. 2004, 51, 414-419. [CrossRef]

38. Wu, R.-Y.; Deng, C.-Y.; Yang, Z.-J.; Weng, H.-Y.; Zhu, T.-J.; Zheng, J.-G. Negative air ions generated by plants upon pulsed electric field stimulation applied to soil. J. Appl. Ecol. 2015, 26, 419-424.

39. Hussain, S.; Iqbal, N.; Brestic, M.; Raza, M.A.; Pang, T.; Langham, D.R.; Safdar, M.E.; Ahmed, S.; Wen, B.; Gao, Y.; et al. Changes in morphology, chlorophyll fluorescence performance and Rubisco activity of soybean in response to foliar application of ionic titanium under normal light and shade environment. Sci. Total. Environ. 2019, 658, 626-637. [CrossRef]

40. Lokstein, H.; Tian, L.; Polle, J.E.; DellaPenna, D. Xanthophyll biosynthetic mutants of Arabidopsis thaliana: Altered nonphotochemical quenching of chlorophyll fluorescence is due to changes in Photosystem II antenna size and stability. Biochim. Biophys. Acta (BBA)-Bioenerg. 2002, 1553, 309-319. [CrossRef]

41. Fernández-Marín, B.; Balaguer, L.; Esteban, R.; Becerril, J.M.; Garcia-Plazaola, J.I. Dark induction of the photoprotective xanthophyll cycle in response to dehydration. J. Plant Physiol. 2009, 166, 1734-1744. [CrossRef] [PubMed] 
42. Liu, P.; Zhou, J.; Hong, Y.; Xie, X. Electric-field enhanced microalgae inactivation using a flow-through copper ionization cell. J. Hazard. Mater. 2020, 400, 123320. [CrossRef]

43. Gateau, H.; Blanckaert, V.; Veidl, B.; Burlet-Schiltz, O.; Pichereaux, C.; Gargaros, A.; Marchand, J.; Schoefs, B. Application of pulsed electric fields for the biocompatible extraction of proteins from the microalga Haematococcus pluvialis. Bioelectrochemistry 2021, 137, 107588. [CrossRef] [PubMed] 